\title{
Soya protein reverses dyslipidaemia and the altered capacity of insulin-stimulated glucose utilization in the skeletal muscle of sucrose-rich diet-fed rats
}

\author{
María E. Oliva, Adriana G. Chicco and Yolanda B. Lombardo* \\ Department of Biochemistry, School of Biochemistry, University of Litoral, Ciudad Universitaria Paraje El Pozo, CC 242 (3000) \\ Santa Fe, Argentina \\ (Received 17 July 2008 - Revised 2 October 2008 - Accepted 13 October 2008 - First published online 15 December 2008)
}

The present study investigates the benefits of dietary intake of soya protein upon dyslipidaemia and insulin resistance in rats chronically (8 months) fed a sucrose-rich $(63 \%)$ diet (SRD). For this purpose, we analysed the effectiveness of soya protein isolate in improving or reversing these metabolic abnormalities. Wistar rats were fed a SRD for 4 months. By the end of this period, stable dyslipidaemia and insulin resistance were present in the animals. From months 4 to 8 , half the animals continued with the SRD and the other half were fed a SRD in which the source of protein casein was substituted by soya. The control group received a diet in which the source of carbohydrate was maize starch. The results showed that: (1) soya protein normalized plasma TAG, cholesterol and NEFA levels in the SRD-fed rats. Moreover, the addition of soya protein reversed the hepatic steatosis. (2) Glucose homeostasis was normalized without changes in circulating insulin levels. Whole-body peripheral insulin sensitivity substantially improved. Besides, soya protein moderately decreases body weight gain limiting the accretion of visceral fat. (3) By shifting the source of dietary protein from casein to soya during the last 4 months of the feeding period it was possible to reverse both the diminished insulin-stimulated glucose oxidation and disposal in the skeletal muscle of SRD-fed rats. This study provides new data showing the beneficial effect of soya protein upon lipid and glucose homeostasis in the experimental model of dyslipidaemia and insulin resistance.

Soya protein: Dyslipidaemia: Insulin resistance: Skeletal muscle

Insulin resistance is a major key factor in the aetiology of the plurimetabolic syndrome cluster disease which includes type 2 diabetes, dyslipidaemia, hypertension, obesity and CVD, among other disturbances ${ }^{(1)}$. Dietary factors undoubtedly influence insulin action and play an important role in the prevention or improvement of these metabolic disorders. In recent years, there has been considerable interest in the effect of dietary soya protein on human health ${ }^{(2)}$. This is based on accumulated evidence that the addition of soya in the diet or the substitution of soya protein for animal protein has been shown to reduce plasma total and LDL- cholesterol and TAG concentrations in man and laboratory animals ${ }^{(3,4)}$. Tovar et al. ${ }^{(5)}$ showed in Zucker obese fa/fa rats that soya protein consumption reduced the accumulation of cholesterol and TAG in the liver, preventing the development of fatty livers. The reduction in hepatic cholesterol was associated with a low expression of liver $\mathrm{X}$ receptor $\alpha$ and its target genes (e.g. $7 \alpha$-hydroxylase and ATP binding cassette A1). Besides, soya protein also decreased lipogenesis through a decrease in the expression of the sterol regulatory elementbinding protein-1 (SREBP1) and several of its target enzymes $^{(5,6)}$. Furthermore, the reduction of hepatic lipids could also be the result of an increase in fatty acid oxidation since soya protein increases PPAR $\alpha$ and carnitin palmityl transferase 1 expression ${ }^{(5)}$. Dietary soya protein could also improve glucose homeostasis and insulin sensitivity ${ }^{(6-11)}$. In this vein, Taha $\&$ Wasif ${ }^{(12)}$ reported that in aloxan diabetic hypercholesterolaemic rats dietary soya flour lowered the elevated plasma glucose level. Davis et al. ${ }^{(13)}$ demonstrated that feeding SHHF $(+\mathrm{cp})$ rats with a soya protein diet for 36 weeks significantly lowered body and liver weights, plasma total cholesterol and both fasting blood glucose and plasma insulin compared to rats fed casein. Moreover, in animal models of obesity, soya protein ingestion limits or reduces body fat accumulation and improves insulin resistance (for a review see Velásquez \& Bhathena ${ }^{(14)}$ ).

Studies from our laboratory ${ }^{(15-18)}$ have reported that rats chronically fed (3-8 months) with a diet rich in sucrose (SRD) developed a stable dyslipidaemia (increased plasma TAG and plasma NEFA levels), moderate hyperglycaemia and insulin resistance. This was accompanied by moderate overweight and visceral adiposity. Islets isolated from these rats showed insulin secretion patterns characterized by the absence of the first peak and enhancement of the second phase of the hormone released in response to glucose. In addition to an ectopic fat deposition in the liver, heart and pancreas tissues, an increase of the lipid storage (TAG, long-chain acyl-CoA, diacylglycerol) as well as the membrane protein

Abbreviations: CD, control diet; SRD, sucrose-rich diet; SRD-S, sucrose-rich diet with soya; SREBP1, sterol regulatory element-binding protein-1. 
kinase $\mathrm{C} \theta$ mass expression and impaired glucose metabolism was observed in the skeletal muscle of the SRD-fed rats ${ }^{(19,20)}$. Interestingly, this animal model exhibits many of the hallmarks present in the plurimetabolic syndrome in man. Several studies examined the effect of dietary soya protein on the SRD-induced insulin resistance and dyslipidaemia in rats. In this regard, Lavigne et al. ${ }^{(21)}$ showed that in Wistar rats fed a diet containing $55 \%$ of sucrose during 4 weeks, soya protein lowered fasting glucose and insulin concentration, and improved peripheral insulin sensitivity compared to rats fed casein. Pfeuffer \& Barth $^{(22)}$ demonstrated that in rats fed the SRD during 7 weeks, the plasma cholesterol concentration and the rates of secretion of VLDL- cholesterol and TAG were lower when soya protein, compared to casein, was the source of dietary protein. The type of protein may improve the metabolic consequences of the consumption of a highsucrose diet. However, to our knowledge there have been no studies focusing on the possible beneficial effects of dietary soya protein on improving or reversing both insulin insensitivity and lipid metabolism in rats fed a SRD for a long time, in which a well-established dyslipidaemia and insulin resistance was present before the source of dietary protein casein was isoenergetically replaced by soya. To test this hypothesis, the present work was designed to evaluate: (1) several aspects involved in lipid metabolism; (2) the whole-body peripheral insulin sensitivity and its possible relationship with the lipidlowering effects of soya protein; and (3) since the skeletal muscle is the major site of insulin-stimulated glucose disposal, we analysed the glucose oxidation (estimated by the activity of the pyruvate dehydrogenase complex (PDHc)), TAG and glycogen storages and glucose-6-phosphate concentration both at the basal state and during a euglycaemic-hyperinsulinaemic clamp in the gastrocnemius muscle (as a representative of the skeletal muscle).

\section{Materials and methods}

\section{Animals and diets}

Male Wistar rats initially weighing $170-185 \mathrm{~g}$ and purchased from the National Institute of Pharmacology (Buenos Aires,
Argentina), were maintained in the animal room under controlled temperature $\left(22 \pm 1^{\circ} \mathrm{C}\right)$, humidity and air flow condition, with a fixed $12 \mathrm{~h}$ light-dark cycle (light 07.00 to 19.00 hours). They were initially fed a standard non-purified diet containing by weight (g/100 g: 63 maize starch, sorghum, wheat, oats, barley), 22 protein, 3.5 fat, 6 fibre, 1 vitamin mixture and 4 salt mixtures (Ralston, Purina, St Louis, MO, USA). After 1 week of acclimation period, they were randomly divided into two groups of rats (control and experimental). The experimental group ( $n$ 78) received a purified SRD containing by weight $(\mathrm{g} / 100 \mathrm{~g}): 62.5$ sucrose, 18 casein-free vitamins, 7 maize oil, 7.5 cellulose, 3.5 salt mixture (AIN93M-MX), 1 vitamin mixture (AIN-93-VX), 0.2 choline chloride, $0 \cdot 3$ DL-methionine ${ }^{(19)}$. The control group (n 30) received the same purified diet but with sucrose replaced by maize starch ((high-starch diet, control diet (CD)). Both groups received each diet for 4 months after which the SRD group of rats was randomly subdivided into three subgroups. The first subgroup ( $n$ 18) was immediately killed for each experiment as described later. The rats in the second subgroup ( $n$ 30) continued on the SRD up to 8 months of feeding. The third subgroup ( $n$ 30; SRD-S) received the SRD in which the source of protein (casein $18 \mathrm{~g} / 100 \mathrm{~g}$ ) had been replaced by soya protein isolate (MP Biomedicals, Solon, $\mathrm{OH}$, USA) for the next 4 months. The control group was fed with the $\mathrm{CD}$ throughout the experimental period. Details on the composition of the diets are given in Table 1.The preparation and handling of the diets have been reported elsewhere ${ }^{(19)}$. Diets were isoenergetic, providing approximately $16.3 \mathrm{~kJ} / \mathrm{g}$ food and were available ad libitum. Diets were prepared every week. The weight of each animal and the energy intake were recorded twice per week during the experimental period in all groups and subgroups of rats. At the end of the experimental period, food was removed at 07.00 hours (end of the dark period), and unless otherwise indicated experiments were performed between 07.00 and 09.00 hours. At least six rats from the three dietary groups were used in each procedure. They were anaesthetized with intraperitoneal pentobarbital $\mathrm{Na}(600 \mathrm{mg} / \mathrm{kg}$ body weight). Blood samples were obtained from the jugular vein and rapidly centrifuged; plasma was either immediately assayed

Table 1. Composition of the experimental diets (based on the AIN-93 diet)

\begin{tabular}{|c|c|c|c|c|c|c|}
\hline \multirow[b]{2}{*}{ Diet ingredients } & \multicolumn{2}{|c|}{ Control diet } & \multicolumn{2}{|c|}{ SRD } & \multicolumn{2}{|c|}{ SRD-S§ } \\
\hline & $\mathrm{g} / 100 \mathrm{~g}$ & \% Energy & $\mathrm{g} / 100 \mathrm{~g}$ & \% Energy & $\mathrm{g} / 100 \mathrm{~g}$ & $\%$ Energy \\
\hline Maize starch & $62 \cdot 5$ & 65 & - & - & - & - \\
\hline Sucrose & - & - & $62 \cdot 5$ & 65 & $62 \cdot 5$ & 65 \\
\hline Casein-free vitamin & 18 & 19 & 18 & 19 & - & - \\
\hline Soya protein & - & - & - & - & 18 & 19 \\
\hline Maize oil & 7 & 16 & 7 & 16 & 7 & 16 \\
\hline Vitamin mix\| & 1 & & 1 & & 1 & \\
\hline Cellulose & $7 \cdot 5$ & & $7 \cdot 5$ & & 7.5 & \\
\hline Salt mix & 3.5 & & 3.5 & & 3.5 & \\
\hline Choline bitartrate & 0.2 & & 0.2 & & 0.2 & \\
\hline DL-Methionine & 0.3 & & 0.3 & & 0.3 & \\
\hline
\end{tabular}

SRD, sucrose-rich diet; SRD-S, SRD with soya protein

$\S$ Soya protein isolate (MP Biomedicals, Solon, OH, USA). Soya protein isolate composition ( $\mathrm{g} / 100 \mathrm{~g})$ : protein, $92 \cdot 0$; water, 6.0; ash, 4.1; fat, 0.8; fibre, 0.25; carbohydrate, 2.85; $\mathrm{Ca}, 0.15 ; \mathrm{P}, 0.8 ; \mathrm{K}, 0.05 ; \mathrm{Na}, 1.3$. Trypsin inhibitor, $4.0-7.3 \mathrm{mg} / \mathrm{g}$.

II AIN-93-VX.

IIN-93M-MX 
or stored at $-20^{\circ} \mathrm{C}$. The liver, skeletal muscle (gastocnemius), epididymal and retroperitoneal adipose tissue were totally removed, weighed and immediately frozen and stored at the temperature of liquid $\mathrm{N}_{2}$. The experimental protocol was approved by the Human and Animal Research Committee of the School of Biochemistry, University of Litoral, Santa Fe, Argentina.

\section{Analytical methods}

Plasma TAG, NEFA, total cholesterol and glucose levels were determined by spectrophotometric methods as previously described $^{(23)}$. The inmunoreactive insulin was measured by the method proposed by Herbert et al. ${ }^{(24)}$. The immunoreactive insulin assays were calibrated against rat insulin standard (Novo Nordisk, Bagsvaerd, Denmark) ${ }^{(24)}$. The TAG and total cholesterol ${ }^{(25)}$ content were determined in homogenates of the frozen liver.

\section{$T A G$ secretion rate}

The TAG secretion rate was evaluated in fasting rats (16$18 \mathrm{~h}$ ) by blocking the removal of plasma TAG with Triton WR 1339 (600 mg/kg body weight) dissolved in $0.9 \% \mathrm{NaCl}$. The TAG secretion rate was calculated from the linear increase of TAG $v$. time, following the procedure described by Lombardo et al. ${ }^{(26)}$.

\section{Intravenous fat tolerance test}

The intravenous fat tolerance test was performed in rats fasted for $16-18 \mathrm{~h}^{(27)}$ by injecting intravenous Intralipid ${ }^{\circledR}$ (Intralipid $^{\circledR} 10 \%$ at $0 \cdot 1 \mathrm{ml} / 100 \mathrm{~g}$ body weight), a soyabean oil fat emulsion, as previously described ${ }^{(23)}$. The first-order rate constant $\left(K_{2}\right)$ of elimination of fat emulsion from the bloodstream (fractional removal rate) was calculated by the least squares methods as described elsewhere ${ }^{(23)}$.

\section{Euglycaemic clamp studies}

Whole-body peripheral insulin sensitivity was measured using the euglycaemic-hyperinsulinaemic clamp technique as previously described elsewhere ${ }^{(19)}$. Briefly, after $5 \mathrm{~h}$ of food deprivation twelve rats from each dietary group were anaesthetized, a blood sample was withdrawn, and glucose and insulin levels were assessed. The gastrocnemius muscle of six rats from each group was rapidly removed (starting clamp studies), frozen, clamped in liquid $\mathrm{N}_{2}$ and stored at $-80^{\circ} \mathrm{C}$ for the determination of TAG, glycogen, glucose-6phosphate, protein and the activity of pyruvate dehydrogenase complex $(\mathrm{PDHc})^{(19,28)}$. In the other six rats, an infusion of highly purified porcine neutral insulin (Actrapid; Novo Nordisk, Bagsvard, Denmark) was administered at 0.8 units/ $(\mathrm{kg} \times \mathrm{h})$ for $2 \mathrm{~h}$. Glycaemia was maintained at a euglycaemic level by infusing glucose $(200 \mathrm{~g} / \mathrm{l})$ at a variable rate. The glucose infusion began 5 min after the insulin infusion started. The blood glucose concentration was measured using a Glucomether Analyzer (Boehringer Mannheim, Indianapolis, IN, USA) within 2 min of the samples being obtained. The glucose infusion rate during the second hour of the clamp study was taken as the net steady state of the whole-body glucose.
In all studies, blood samples $(0.3 \mathrm{ml})$ for insulin determination $^{(24)}$ were obtained at 60,90 and $120 \mathrm{~min}$. Details of the methodology have been previously given ${ }^{(19)}$. At the end of the clamp period, the gastrocnemius muscle was rapidly removed, frozen in liquid $\mathrm{N}_{2}$, and stored at $-80^{\circ} \mathrm{C}$ for subsequent analysis of metabolites and enzyme activity as described earlier.

\section{Extraction and assays for pyruvate dehydrogenase complex activity}

The extraction of PDHc from the gastrocnemius muscles was described in detail elsewhere ${ }^{(19,20)}$. The activity of PDHc was spectrophotometrically determined at $30^{\circ} \mathrm{C}$ by measuring the reduction of $\mathrm{NAD}^{+(19,28)}$. The PDHc activity was expressed as nmol NADH formed/min per $\mathrm{g}$ wet weight tissue and per mg soluble protein.

\section{Statistical analysis}

Sample sizes were calculated on the basis of measurements previously made with rats fed either a CD or a $\operatorname{SRD}^{(15,16,18,29)}$, considering an $80 \%$ power. Results were expressed as means and their standard errors. Statistical comparisons were done transversely between different dietary groups. The statistical significance between groups was determined by one-way ANOVA, with one factor (diet) followed by the inspection of all differences between pairs of means by the Newman-Keuls test. Differences having $P$ values lower than 0.05 were considered to be statistically significant ${ }^{(30)}$. In all cases the interclass correlation coefficients were at least $0 \cdot 73$.

\section{Results}

\section{Body weight gain and energy intake}

Body weight and energy intake were carefully monitored in all groups of rats throughout the experimental period. Table 2 depicts the body weight gain and energy intake recorded in each experimental group. As previously shown ${ }^{(19)}$, comparable weight-gain and energy intake were recorded in SRD and $\mathrm{CD}$ rats during the first 4 months on their respective diets. However, a significant increase in both parameters was observed in the rats that continued with the SRD up to 8 months. When the source of dietary protein in the SRD was replaced for the last 4 months on the diet (SRD-S), both energy intake and weight gain remained similar to those observed in the rats fed the CD. Moreover, the increased visceral adiposity (epididymal weight, $\mathrm{g} / 100 \mathrm{~g}$ body weight) observed in the SRD-fed rats was improved when the source of protein in the diet was soya instead of casein. Values were as follows (six animals per group): 1.83 (SEM 0.11) in the CD-fed rats, 2.77 (SEM 0.14) in the SRD and 2.39 (SEM 0.09) in the SRD-S $(P<0.001$ in SRD $v$. CD; $P<0.05$ in the SRD $v$. SRD-S; $P<0.01$ in SRD-S $v$. CD). A similar pattern was observed in retroperitoneal weight in each experimental group (data not shown). 
Table 2. Body weight gain and energy intake of rats fed on control diet (CD), sucrose-rich diet (SRD) or the SRD with soya protein (SRD-S)§ (Mean values with their standard errors)

\begin{tabular}{|c|c|c|c|c|c|c|c|c|c|c|c|c|c|}
\hline \multirow[b]{2}{*}{ Diet } & \multicolumn{2}{|c|}{$\begin{array}{l}\text { Initial body } \\
\text { wt (g) }\end{array}$} & \multicolumn{2}{|c|}{$\begin{array}{l}\text { Body wt at } \\
\text { month } 4 \text { (g) }\end{array}$} & \multicolumn{2}{|c|}{$\begin{array}{l}\text { Energy intake } \\
\text { (initial to } \\
\text { month 4) } \\
(\mathrm{kJ} / \mathrm{d})\end{array}$} & \multirow{2}{*}{$\begin{array}{l}\text { Diet for } \\
\text { months } 4-8\end{array}$} & \multicolumn{2}{|c|}{$\begin{array}{l}\text { Body wt at } \\
\text { month } 4 \text { (g) }\end{array}$} & \multicolumn{2}{|c|}{$\begin{array}{l}\text { Body wt at } \\
\text { month } 8(\mathrm{~g})\end{array}$} & \multicolumn{2}{|c|}{$\begin{array}{l}\text { Energy intake } \\
\text { (months } 4-8) \\
(\mathrm{kJ} / \mathrm{d})\end{array}$} \\
\hline & Mean & SEM & Mean & SEM & Mean & SEM & & Mean & SEM & Mean & SEM & Mean & SEM \\
\hline CD $(n 30)$ & 181.6 & 4.6 & $400 \cdot 0$ & $8 \cdot 1$ & $265 \cdot 8$ & $6 \cdot 2$ & $\mathrm{CD}(n 30)$ & $407 \cdot 0$ & $7 \cdot 7$ & $478 \cdot 6$ & $13 \cdot 2$ & $264 \cdot 8$ & $6 \cdot 3$ \\
\hline \multirow[t]{2}{*}{ SRD $(n 78)$} & $185 \cdot 3$ & 4.4 & $415 \cdot 1$ & $8 \cdot 3$ & $263 \cdot 7$ & 3.6 & SRD ( $n$ 30) & 417.5 & $7 \cdot 2$ & $525 \cdot 1^{* *}$ & $10 \cdot 7$ & $334 \cdot 7^{\star \star \star}$ & $8 \cdot 4$ \\
\hline & & & & & & & SRD-S ( $n 30)$ & $408 \cdot 7$ & 9.7 & $492 \cdot 9$ & $7 \cdot 2$ & $270 \cdot 0$ & $4 \cdot 8$ \\
\hline
\end{tabular}

Mean values were significantly different from those of the CD and SRD-S: ${ }^{\star \star} P<0.01,{ }^{\star \star \star} P<0.001$.

$\S$ For details of procedures and diets, see the Materials and methods section and Table 1.

\section{Plasma metabolite levels}

After the 4- and 8-month feeding periods, plasma TAG, NEFA, total cholesterol and glucose levels were significantly higher in the SRD-fed rats than in the CD group $(P<0 \cdot 01)$ (Table 3$)$. The presence of soya protein in the SRD (instead of casein) for the last 4 months of the diet was able to return all the listed metabolites to the levels observed in the CD-fed rats. Interestingly, as mentioned earlier, rats fed SRD-S showed a significant decrease of body weight when compared to SRDfed rats. Therefore, an analysis of covariance between plasma glucose levels and final body weight in SRD and SRD-S rats was performed. The results showed $r 0 \cdot 84, P<0 \cdot 01$ ( $n$ 12). At the end of the experimental period, no statistically significant differences in plasma insulin levels were observed among all dietary groups.

\section{Liver cholesterol and TAG content, TAG secretion rate and} fractional removal rate of fat emulsion

The rats fed the SRD for 4 or 8 months showed a significant increase $(P<0.001)$ of TAG content and in vivo TAG secretion rate associated with a decrease of fractional removal rate $\left(K_{2}, \% / \mathrm{min}\right)$ of the intravenously injected fat emulsion (Intralipid ${ }^{\circledR}$ ) compared to age-matched CD-fed rats (Table 4). The substitution of casein for soya protein in the SRD for the last 4 months on the diet significantly decreased liver TAG content and liver TAG secretion rate and increased the removal rate of TAG from circulation, with values similar to those observed in the CD-fed rats (Table 4). Moreover, the SRD-fed rats showed an increase of liver total cholesterol content that was completely normalized when the casein present in the SRD rats was replaced by soya protein during the last 4 months on the diet. Values were as follows (six animals per group): 3.51 (SEM 0.08) $\mu \mathrm{mol} / \mathrm{g}$ wet tissue in the CD-fed rats, 4.81 (SEM 0.07) in the SRD 4 months, 4.95 (SEM 0.09) in the SRD 8 months and 3.48 (SEM 0.05) in the SRD-S $(P<0.001$ in SRD 4 and in SRD 8 months $v$. CD and SRD-S $)$.

\section{Glucose infusion rate}

In order to assess the effect of soya protein on whole-body peripheral insulin sensitivity (insulin resistance), a euglycaemic-hyperinsulinaemic clamp study was performed in rats fed CD, SRD and SRD-S, at 8 months on the diet. Blood glucose was clamped at 5.5-6.0 mM. Postprandial glucose concentration at $5 \mathrm{~h}$ before the clamp was as follows (six rats per group): 5.85 (SEM 0.15 ) $\mathrm{mm}$ in rats fed $\mathrm{CD}$, 7.87 (SEM 0.12) in the SRD group and 6.1 (SEM 0.22) in the SRD-S group $(P<0 \cdot 001$ in SRD v. CD and SRD-S). In all dietary groups, plasma insulin levels were similar to those obtained at the end of the dark period (data not shown). Glucose infusion rate was significantly decreased $(P<0 \cdot 01)$ in the SRD-fed rats compared to age-matched $\mathrm{CD}$-fed rats. Moreover, although glucose infusion rate was significantly higher in SRD-S compared to the SRD-fed group $(P<0 \cdot 01)$, values were still significantly different $(P<0 \cdot 05)$ from those recorded in the CD-fed rats (Fig. 1). There were no differences in haematocrit from the start to the end of the clamp (data not shown).

Table 3. Plasma TAG, NEFA, total cholesterol, glucose and insulin levels of rats fed the control diet (CD), sucrose-rich diet (SRD) or the SRD with soya protein (SRD-S)§

(Mean values with their standard errors for six animals per group)

\begin{tabular}{|c|c|c|c|c|c|c|c|c|c|c|}
\hline \multirow[b]{2}{*}{ Diet } & \multicolumn{2}{|c|}{ TAG (mM) } & \multicolumn{2}{|c|}{ NEFA ( $\mu \mathrm{M})$} & \multicolumn{2}{|c|}{$\begin{array}{l}\text { Total cholesterol } \\
(\mathrm{mm})\end{array}$} & \multicolumn{2}{|c|}{ Glucose (mм) } & \multicolumn{2}{|c|}{ Insulin $(\mu \mathrm{U} / \mathrm{ml})$} \\
\hline & Mean & SEM & Mean & SEM & Mean & SEM & Mean & SEM & Mean & SEM \\
\hline CD (8 months) & 0.64 & 0.04 & $310 \cdot 0$ & $10 \cdot 0$ & $2 \cdot 18$ & 0.08 & 6.00 & 0.17 & $70 \cdot 2$ & $5 \cdot 3$ \\
\hline SRD (4 months) & $1.40^{\star *}$ & 0.09 & $715 \cdot 0^{\star \star}$ & $52 \cdot 0$ & $3.09^{\star \star}$ & 0.07 & $7 \cdot 95^{\star \star}$ & 0.19 & 73.9 & 6.5 \\
\hline SRD (8 months) & $1 \cdot 35^{\star *}$ & 0.08 & $730 \cdot 0^{\star \star}$ & $80 \cdot 0$ & $3 \cdot 24^{\star *}$ & 0.08 & $8 \cdot 20^{\star *}$ & 0.19 & $76 \cdot 3$ & $7 \cdot 7$ \\
\hline SRD (4 months) + SRD-S (4 months) & 0.64 & 0.07 & $320 \cdot 0$ & $40 \cdot 0$ & $2 \cdot 08$ & 0.15 & $6 \cdot 72$ & 0.10 & $80 \cdot 4$ & $7 \cdot 4$ \\
\hline
\end{tabular}

Mean values were significantly different from those of the CD and SRD-S: ${ }^{* \star} P<0.01$.

$\S$ For details of procedures and diets, see the Materials and methods section and Table 1. 
Muscle TAG, glucose-6-phosphate and glycogen content, and pyruvate dehydrogenase complex activity at the start of euglycaemic-hyperinsulinaemic clamp studies

At the start of the clamp ( 0 min), the SRD-fed rats showed a significant increase of gastrocnemius muscle TAG levels without changes in glycogen and glucose-6-phosphate content and

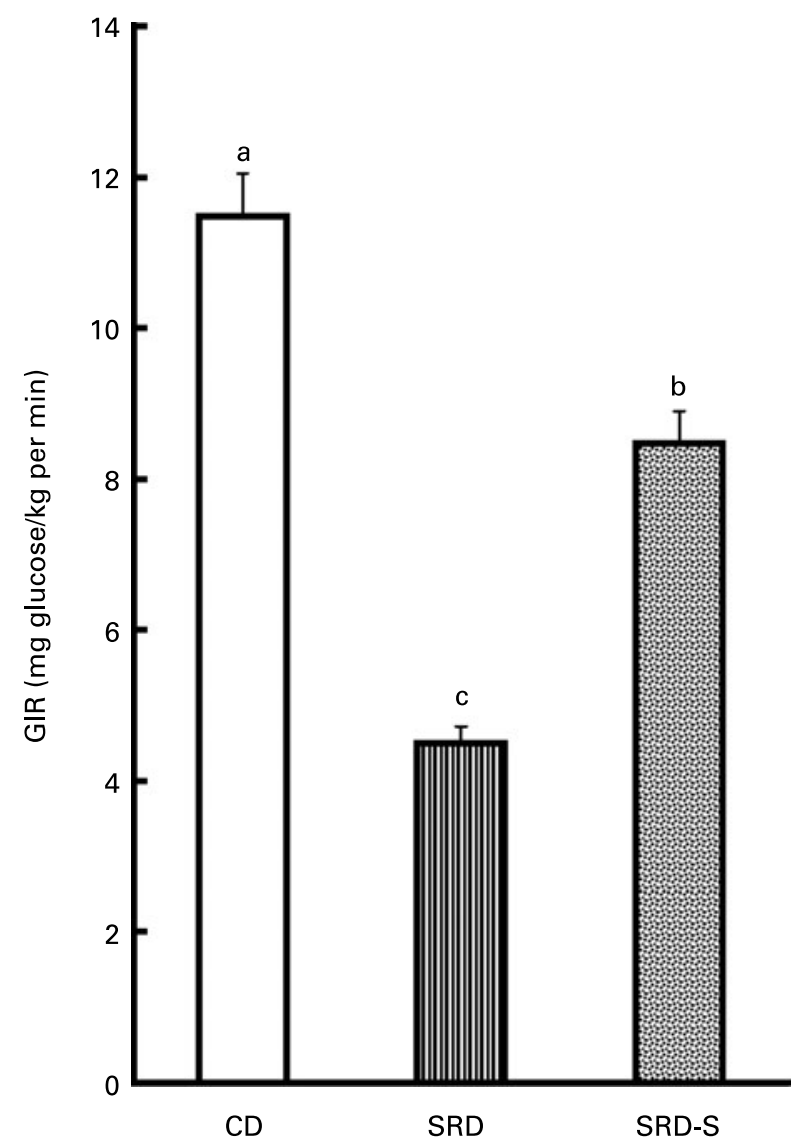

Fig. 1. Glucose infusion rate (GIR) during the euglycaemic-hyperinsulinaemic clamp in rats fed control diet (CD), sucrose-rich diet (SRD) or SRD with soya protein (SRD-S) at the end of the experimental period. Values are means with their standard errors depicted by vertical bars (six animals per group). ${ }^{a, b, c}$ Mean values with unlike letters were significantly different $(P<0.05)$. a significant decrease of activity of PDHa compared to CD-fed rats (Table 5). When the source of protein in the SRD (casein) was replaced by soya protein for the last 4 months of the diet, no changes in glycogen and glucose-6-phosphate levels were recorded among the groups. Furthermore, TAG content and the PDHa activity returned to control values. No differences were observed in total PDHc activity in gastrocnemius muscle of rats fed on the different diets expressed both as either $\mathrm{mU} / \mathrm{g}$ wet tissue or $\mathrm{mU} / \mathrm{mg}$ protein (data not shown). A similar pattern was observed in all dietary groups at the end of the dark period (data not shown).

Muscle TAG, glucose-6-phosphate and glycogen content, and pyruvate dehydrogenase complex activity at the end of euglycaemic-hyperinsulinaemic clamp studies

At the end of the clamp study, muscle TAG contents reached values similar in all three dietary groups. Interestingly, this increase was up to $70-80 \%$ in both the CD and the SRD-S but only $6 \%$ in the SRD-fed rats compared to the basal state (Fig. 2(A)). Insulin stimulated muscle glycogen and glucose-6-phosphate deposition in the CD-fed rats. However, no significant changes in these metabolites were observed in the SRD-fed group. When the source of protein in the SRD (casein) was replaced by soya in the last 4 months of the experimental period both glucose-6-phosphate and glycogen content increased, reaching values similar to those observed in the CD-fed rats (Fig. 2(B, C)). No changes in PDHa activity were observed under insulin stimulation among all three dietary groups at the end of the clamp (data not shown).

\section{Discussion}

In the present study, soya protein was administered instead of casein as a dietary source of protein to analyse the benefits of this nutritional intervention on a non-genetic model of stable dyslipidaemia and insulin insensitivity induced in normal rats by feeding them with a SRD for a long period (8 months). The new major findings of the present work are the following: (1) soya protein markedly reduced the in vivo hepatic TAG secretion rate and enhanced its removal from the circulation leading to a normalization of plasma TAG levels. Besides, both plasma cholesterol and NEFA levels returned to normal values when soya protein replaced the casein present in the 
Table 5. Gastrocnemius TAG, glucose-6-phosphate and glycogen content, and pyruvate dehydrogenase complex (PDHa) activity in rats fed a control diet (CD), sucrose-rich diet (SRD) or SRD with soya protein (SRD-S)§

(Mean values with their standard errors for six animals per group)

\begin{tabular}{|c|c|c|c|c|c|c|c|c|}
\hline \multirow[b]{2}{*}{ Diet } & \multicolumn{2}{|c|}{$\begin{array}{c}\text { TAG ( } \mu \mathrm{mol} / \mathrm{g} \\
\text { wet tissue) }\end{array}$} & \multicolumn{2}{|c|}{$\begin{array}{l}\text { Glycogen } \\
\text { ( } \mu \text { mol/g wet } \\
\text { tissue) }\end{array}$} & \multicolumn{2}{|c|}{$\begin{array}{c}\text { Glucose-6- } \\
\text { phosphate } \\
\text { ( } \mu \mathrm{mol} / \mathrm{g} \text { wet } \\
\text { tissue) }\end{array}$} & \multicolumn{2}{|c|}{$\begin{array}{l}\text { PDHa activity } \\
\text { (\% of total } \\
\text { PDHa) }\end{array}$} \\
\hline & Mean & SEM & Mean & SEM & Mean & SEM & Mean & SEM \\
\hline CD (8 months) & $3 \cdot 84$ & 0.36 & 4.70 & 0.18 & 0.44 & 0.05 & 37.6 & $2 \cdot 3$ \\
\hline SRD (8 months) & $7 \cdot 25^{\star \star}$ & $0 \cdot 81$ & $5 \cdot 20$ & 0.40 & 0.40 & 0.05 & $19 \cdot 2^{\star \star \star}$ & 1.5 \\
\hline SRD (4 months) + SRD-S (4 months) & $4 \cdot 12$ & 0.55 & $4 \cdot 14$ & 0.43 & 0.50 & 0.02 & $38 \cdot 6$ & $1 \cdot 1$ \\
\hline
\end{tabular}

Mean values were significantly different from those of the CD and SRD-S: ${ }^{\star \star} P<0.01,{ }^{\star \star \star} P<0.001$.

$\S$ For details of procedures and diets, see Materials and Methods section and Table 1.

SRD during the last 4 months of the experimental period. Moreover, the addition of soya protein reversed the hepatic steatosis present in the rats fed a SRD. (2) Glucose homeostasis returned to normal values despite the fact that no significant changes occurred in the circulating insulin levels. Whole-body peripheral insulin sensitivity substantially improved, reaching values approaching those of the CD group. Besides, soya protein moderately decreased body weight gain, limiting the accretion of visceral fat. (3) By shifting the source of dietary protein from casein to soya during the last 4 months of the feeding period, it was possible to reverse both the diminished capacity of insulin-stimulated glucose oxidation and disposal in the skeletal muscle of SRD-fed rats.

Confirming previous studies ${ }^{(15-17)}$, an increase of the VLDL-TAG secretion rate and a defective removal of TAG from the circulation led to a steady state of hypertriglyceridaemia in rats chronically (up to 8 months) fed a SRD. Diets rich in sucrose or fructose induced the activities of key enzymes involved in lipogenesis through an activation of the gene expression of SREBP-1 and decreasing the activities of the enzymes related to fatty acid oxidation by down-regulation of PPAR $\alpha$ resulting in an increase of both VLDL-TAG secretion and liver TAG storage. Besides, Soria et al. ${ }^{(29)}$ demonstrated that in long-term SRD-fed rats there is an increased release of NEFA from adipose tissue to non-adipose tissue that in turn could enhance hepatic sterification of NEFA to TAG and also contribute to the development of liver steatosis. In the present study on rats fed a SRD, in which during the last 4 months of the feeding period casein was replaced by soya protein, it is shown that the substitution for this macronutrient plays a key role in the changes observed in lipid metabolism and insulin sensitivity. Both the VLDLTAG secretion rate and liver TAG and cholesterol depot were completely normalized, possibly through the mechanism that included opposite changes in SREBP1 and PPAR $\alpha$ expression leading to a significant decrease of hepatic de novo lipogenesis ${ }^{(5)}$. In this regard, there is evidence that soya protein prevents the overexpression of SREBP1 and several of its target genes such as fatty acid synthase, malic enzyme, stearoyl-CoA desaturase 1 and $\Delta 5$ and $\Delta 6$ desaturases
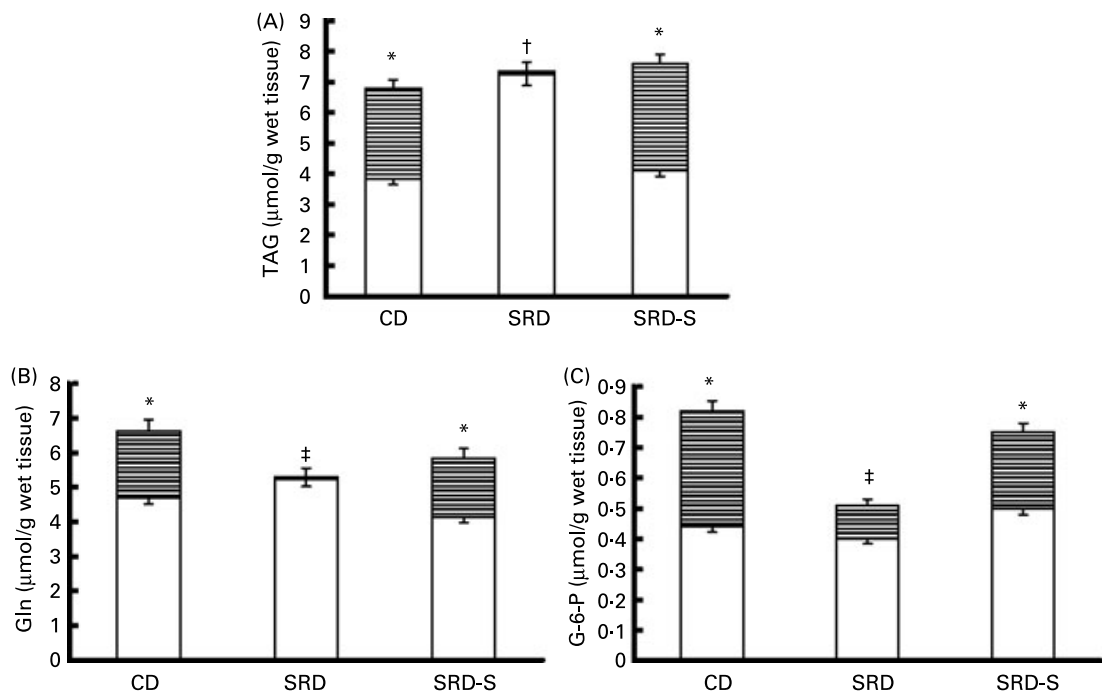

Fig. 2. TAG (A), glycogen (GIn; B) and glucose-6-phosphate (G-6-P; C) levels in gastrocnemius muscle at the start (0 min; $\square$ ) and at the end (120 min; 目) of the clamp studies in rats fed control diet (CD), sucrose-rich diet (SRD) or SRD with soya protein (SRD-S) at the end of the experimental period. Values are means, at the start and at the end of the clamp, with their standard errors depicted by vertical bars (six animals per group). Mean values were significantly different from those of CD or SRD-S rats at the start $v$. the end of the clamp: ${ }^{\star} P<0.05$. Mean values were significantly different from those of SRD rats at the start $v$. either CD or SRD-S rats at the start of the clamp: $† P<0.05$. Mean values were significantly different from those of SRD rats at the end $v$. either CD or SRD-S rats at the end of the clamp: $\ddagger P<0.05$. 
decreasing lipid accumulation ${ }^{(5)}$. Furthermore, plasma TAG levels and clearance reached values similar to those recorded in CD-fed rats. Besides, the addition of soya protein decreased the excessive availability of plasma NEFA. This, in turn, contributed to decrease the synthesis and secretion of VLDL-TAG from the liver, limiting the formation of LDL particles and, therefore, reducing plasma TAG and cholesterol levels. In addition to the reduction of lipogenesis, Tovar et al. ${ }^{(5)}$ showed that in rats fed soya protein the reduction of serum cholesterol was associated with a stimulation of bile acid synthesis possibly through the induction of the enzyme cholesterol $7 \alpha$-hydroxylase 1 . Interestingly, in line with the present results, in vitro studies by Sugano et al. ${ }^{(31)}$ showed a decrease of hepatic secretion of TAG and cholesterol in rats fed soya protein in a SRD during a short period of time (few weeks) when compared to those fed casein. Comparable data were recorded by Pfeuffer \& Barth ${ }^{(32)}$ in rats at different ages (10 or 25 weeks old). Thus, in the SRD-fed rats, the reversion of dyslipidaemia suggests that the principal action of soya protein on hepatic lipid metabolism involves a shift from lipid synthesis and storage to lipid oxidation and, therefore, both mechanisms contribute to the lipid-lowering effect of soya protein. However, we cannot discard the possibility that other mechanisms such as changes in insulin to glucagon ratio, amino acid composition, a rise in thyroid hormone levels as well as the presence of other components in the soya protein including lipids, fibre and isoflavones could also contribute to the hypolipidaemic effect on blood and liver in the SRD-fed rats ${ }^{(7,14,33-37)}$.

Previous studies using different animal models of obesity demonstrated that dietary soya protein diminished body weight and visceral fat ${ }^{(14)}$. In the present work, visceral adiposity was significantly reduced as well as the increases of weight gain and energy intake recorded in long-term SRD-fed rats when soya protein replaced casein as a source of dietary protein. Besides, all these parameters reached values similar to those recorded in the CD-fed animals. The present results do not provide data concerning the mechanism involved in the improvement of visceral adiposity and body weight after soya protein administration in the SRD-fed rats. Moreover, since the animals were fed ad libitum, it is worth considering the risk of uncontrollable bias associated with body weight changes between the groups. On the other hand, in agreement with the present data, Torre-Villalvazo et al. ${ }^{(38)}$ demonstrated that normal Wistar rats fed a soya protein in a high-fat diet gained less weight than those fed casein, in part due to an increase of their thermogenic capacity mediated by mitochondrial uncoupling protein 1 . Iritani et al. ${ }^{(39)}$ also recorded a lower body gain weight in Wistar fatty rats fed a soya protein during a short period of time compared to those fed casein. In these rats, an increase of triiodothyronine production seemed to play a role in the reduction of body weight. Furthermore, Tovar et al. ${ }^{(5)}$ showed that dietary soya protein reduced the SREBP1 expression in adipocytes of ZDF fa/fa rats preventing their hypertrophy.

As previously shown elsewhere ${ }^{(15)}$ and now confirmed in the present study, long-term SRD feeding to rats develops abnormal glucose homeostasis and whole-body insulin insensitivity without changes in basal plasma insulin levels. Insulin resistance is strongly correlated with an increase of both plasma TAG and NEFA levels and muscle TAG storage. In this regard, dyslipidaemia and a substantial increase in TAG concentration within the gastrocnemius muscle were shown in rats fed a long-term SRD. Skeletal muscle is the most important tissue for insulin-mediated glucose disposal. In the present work, the euglycaemic clamp was performed at supraphysiological doses of insulin. Therefore, it could be expected to result in a near maximal rate of insulin-stimulated glucose uptake. Under this experimental condition in the SRDfed rats, the decreased capacity of glucose oxidation in the basal state and during the euglycaemic clamp, mainly due to a significant reduction of the PDHa activity, was completely normalized when soya replaced casein as a source of protein. Dietary soya protein reversed the impaired insulin-stimulated glycogen storage (glycogen concentrations reached values similar to those of the CD group), as well as hyperglycaemia, and substantially improved the whole-body peripheral insulin resistance. Additionally, as mentioned earlier, plasma NEFA levels returned to normal values, indicating a reduced spillover of this metabolite from adipose tissue to non-adipose tissue including skeletal muscle, mainly by increased insulin sensitivity. Thus, the present data suggest that the hypolipidaemic effect of soya protein decreases the availability and oxidation of lipid fuel within the skeletal muscle of SRD-fed rats and could in turn restore glucose oxidation and contribute to increase peripheral insulin sensitivity ${ }^{(40)}$. In this vein, Lavigne et al. ${ }^{(21)}$, during a euglycaemic-hyperinsulinaemic clamp, have recently shown that both glucose disposal and plasma glucose disappearance rates were higher in rats fed soya protein in a SRD for a short period of time (4 weeks) compared to those fed casein. Furthermore, in these rats soya protein decreased plasma TAG levels. However, we cannot discard the possibility that other proposed mechanisms by which soya protein may improve glucose homeostasis and insulin action could contribute to the present findings. Among these mechanisms, there is experimental evidence suggesting that soya protein improves insulin resistance and lipid levels by activating $\operatorname{PPAR}^{(7,8)}$. Iritani et al. ${ }^{(9)}$ reported that dietary soya protein in a saturated high-fat diet improved insulin sensitivity by increasing insulin receptor mRNA level in liver and adipose tissue, while plasma glucose levels were not significantly affected. Moreover, differences in the amino acid composition of dietary proteins have also been suggested to mediate protein-dependent changes in glucose and insulin dynamics $^{(10,11)}$.

In brief, the present study provides new data showing that in SRD-fed rats, in the presence of a stable dyslipidaemia and insulin resistance, the parallel effect on insulin sensitivity, glucose and lipid homeostasis and visceral adiposity attained through the manipulation of dietary soya protein suggests a role for this macronutrient in the management of these metabolic abnormalities.

\section{Acknowledgements}

A preliminary report was presented at the XV Congreso de Endocrinología y Metabolismo, Buenos Aires, Argentina, September 2007. The present study was carried out with the financial support of the Agencia Nacional de Promoción Científica y Tecnológica (ANPCyT). U.N.Litoral, CONICET, Grants 
PICTO 05-35 670 BID 1728 OC/AR 2005, PIP no. 5619/2005 and CI + D 11/206. M. E. O. was involved in the analysis of VLDL-TAG secretion rate, the intravenous fat tolerance test of fat emulsion, and the analytical methods of TAG, NEFA, cholesterol, glucose and immunoreactive insulin. A. G. C. was involved in the analysis of the euglycaemic-hyperinsulinaemic clamp and contributed to the discussion of the manuscript. Y. B. L. wrote the manuscript and discussed it with the whole group of authors. There are no conflicts of interest among members of the group.

\section{References}

1. Cheal KL, Abbasi F, Lamendola C, et al. (2004) Relationship to insulin resistance of the Adult Treatment Panel III diagnostic criteria for identification of the metabolic syndrome. Diabetes 53, 1195-1200.

2. Food and Drug Administration (1999) Food labelling: health claims; soy protein and coronary heart disease. Food and drug administration, HHS. Final rule. Fed Regist 64, 57700-57733.

3. Carroll KK \& Kurowska EM (1995) Soy consumption and cholesterol reduction: review of animal and human studies. J Nutr 125, 594-597.

4. Anderson JW, Johnstone BM \& Cook-Newell ME (1995) Metaanalysis of the effects of soy protein intake of serum lipids. $N$ Engl J Med 333, 276-282.

5. Tovar AR, Torre-Villalvazo I, Ochoa M, et al. (2005) Soy protein reduces hepatic lipotoxicity in hyperinsulinemic obese Zucker fa/fa rats. J Lipid Res 46, 1823-1832.

6. Ascencio C, Torres N, Isoard-Acosta F, et al. (2004) Soy protein affects serum insulin and hepatic SREBP-1 mRNA and reduces fatty liver in rats. $J$ Nutr $\mathbf{1 3 4}, 522-529$.

7. Mezei O, Banz WJ, Steger RW, et al. (2003) Soy isoflavones exert antidiabetic and hypolipidemic effects through the PPAR pathways in obese zucker rats and murine RAW 264.7 cells. J Nutr 133, 1238-1243.

8. Morifuji M, Sanbongi C \& Sugiura K (2006) Dietary soya protein intake and exercise training have an additive effect on skeletal muscle fatty acid oxidation enzyme activities and mRNA levels in rats. Br J Nutr 96, 469-475.

9. Iritani N, Sugimoto T, Fukuda H, et al. (1997) Dietary soybean protein increases insulin receptor gene expression in Wistar fatty rats when dietary polyunsaturated fatty acid level is low. J Nutr 127, 1077-1083.

10. Sanchez A \& Hubbard RW (1991) Plasma amino acids and the insulin/glucagon ratio as an explanation for the dietary protein modulation of atherosclerosis. Med Hypotheses 36, 27-32.

11. Sugano M, Ishiwaki N \& Nakashira K (1984) Dietary proteindependent modification of serum cholesterol level in rat. Significance of the arginine/lysine ratio. Ann Nutr Metab 28, 192-199.

12. Taha SA \& Wasif MM (1996) Hypoglycemic effect and protein nutritive quality of soy and methionine-supplemented whole durum pasta products. Nahrung 40, 281-287.

13. Davis J, Steinle J, Higginbotham DA, et al. (2005) Soy protein influences insulin sensitivity and cardiovascular risk in male lean SHHF rats. Horm Metab Res 37, 309-315.

14. Velásquez MT \& Bhathena SJ (2007) Role of dietary soy protein in obesity. Int $J$ Med Sci 4, 72-82.

15. Chicco A, Basabe JC, Karabatas L, et al. (2000) Troglitazone (CS-045) normalizes hypertriglyceridemia and restores the altered patterns of glucose-stimulated insulin secretion in dyslipidemic rats. Metabolism 49, 1346-1351.

16. Fortino A, Lombardo YB \& Chicco A (2007) The reduction of dietary sucrose improves dyslipidemia, adiposity and insulin secretion in an insulin-resistant rat model. Nutrition $\mathbf{2 3}$, 489-497.

17. Lombardo YB, Hein G \& Chicco A (2007) Metabolic syndrome: effects of $n$-3 PUFAs on a model of dyslipidemia, insulin resistance and adiposity. Lipids 42, 427-437.

18. Pighin D, Karabatas L, Rossi A, et al. (2003) Fish oil affects pancreatic fat storage, pyruvate dehydrogenase complex activity and insulin secretion in rats fed a sucrose-rich diet. $J$ Nutr 133, 4095-4101.

19. Chicco A, D'Alessandro ME, Karabatas L, et al. (2003) Muscle lipid metabolism and insulin secretion are altered in insulinresistant rats fed a high sucrose diet. $J$ Nutr 133, 127-133.

20. D'Alessandro ME, Chicco A \& Lombardo YB (2006) A long sucrose-rich diet increases triacylglycerol content and membrane $\mathrm{nPKC} \theta$ expression and alters glucose metabolism in skeletal muscle of rat. Nutr Res 26, 289-296.

21. Lavigne C, Marette A \& Jacques H (2000) Cod and soy proteins compared with casein improve glucose tolerance and insulin sensitivity in rats. Am J Physiol Endocrinol Metab 278, E491-E500.

22. Pfeuffer M \& Barth CA (1992) Dietary sucrose but not starch promotes protein-induced differences in rates of VLDL secretion and plasma lipid concentrations in rats. J Nutr 122, 1582-1586.

23. Chicco AG, D'Alessandro ME, Hein GJ, et al. (2008) Dietary chia seed (Salvia hispanica L.) rich in $\alpha$-linolenic acid improves adiposity and normalises hypertriacylglycerolaemia and insulin resistance in dyslipidaemic rats. Br J Nutr (Epublication ahead of print version 20 May 2008).

24. Herbert V, Lau KS, Gottlierb CH, et al. (1965) Coated charcoal immunoassay of insulin. J Clin Endocrinol Metab 25, 1375-1384.

25. Lombardo YB, Chicco A, Basilico MZ, et al. (1985) Effect of brominated vegetable oils on heart lipid metabolism. Lipids 20, 425-432.

26. Lombardo YB, Chicco A, D’Alessandro ME, et al. (1996) Dietary fish oil normalize dyslipidemia and glucose intolerance with unchanged insulin levels in rats fed a high sucrose diet. Biochim Biophys Acta 1299, 175-182.

27. Rössner S (1974) Studies on an intravenous fat tolerance test. Methodological, experimental and clinical experiences with Intralipid. Acta Med Scand Suppl 564, 1-24.

28. D'Alessandro ME, Chicco A, Karabatas L, et al. (2000) Role of skeletal muscle on impaired insulin sensitivity in rats fed a sucrose-rich diet: effect of moderate levels of dietary fish oil. J Nutr Biochem 11, 273-280.

29. Soria A, D'Alessandro ME \& Lombardo YB (2001) Duration of feeding on a sucrose-rich diet determines metabolic and morphological changes in rat adipocytes. J Appl Physiol 91, 2109-2116.

30. Snedecor GWP \& Cochran WG (1967) Statistical Methods. Ames: Iowa State University Press.

31. Sugano M, Tanaka K \& Ide T (1982) Secretion of cholesterol, triglyceride and apolipoprotein A-I by isolated perfused liver from rats fed soybean protein and casein or their amino acid mixtures. $J$ Nutr 112, 855-862.

32. Pfeuffer M \& Barth CA (1986) Modulation of very low-density lipoprotein secretion by dietary protein is age-dependent in rats. Ann Nutr Metab 30, 281-288.

33. Potter SM (1995) Overview of proposed mechanisms for the hypocholesterolemic effect of soy. J Nutr 125, 3 Suppl., 606S-611S.

34. Ali AA, Velasquez MT, Hansen CT, et al. (2005) Modulation of carbohydrate metabolism and peptide hormones by soybean isoflavones and probiotics in obesity and diabetes. J Nutr Biochem 16, 693-699.

35. Demonty I, Lamarche B, Deshaies Y, et al. (2002) Role of soy isoflavones in the hypotriglyceridemic effect of soy protein in the rat. $J$ Nutr Biochem 13, 671-677. 
36. Tovar AR, Ascencio C \& Torres N (2002) Soy protein, casein, and zein regulate histidase gene expression by modulating serum glucagon. Am J Physiol Endocrinol Metab 283, E1016-E1022.

37. Torres N, Torre-Villalvazo I \& Tovar AR (2006) Regulation of lipid metabolism by soy protein and its implication in diseases mediated by lipid disorders. J Nutr Biochem 17, 365-373.

38. Torre-Villalvazo I, Tovar AR, Ramos-Barragán VE, et al. (2008) Soy protein ameliorates metabolic abnormalities in liver and adipose tissue of rats fed a high fat diet. $J$ Nutr $\mathbf{1 3 8}$, $462-468$.

39. Iritani N, Hosomi H, Fukuda H, et al. (1996) Soybean protein suppresses hepatic lipogenic enzyme gene expression in Wistar fatty rats. $J$ Nutr 126, 380-388.

40. Randle PJ (1999) Regulatory interactions between lipids and carbohydrates: the glucose fatty acid cycle after 35 years. Diabetes Metab Rev 14, 263-283. 